\title{
The Effects of Zinc Oxide Nanoparticles on Drought Stress in Moringa peregrina Populations
}

\author{
Leila Foroutan ${ }^{1}$, Mahmood Solouki ${ }^{*}$, Vahid Abdossi ${ }^{1}$, Barat Ali Fakheri ${ }^{2}$, Nafiseh Mahdinezhad ${ }^{2}$, \\ Kamal Gholamipourfard ${ }^{3}$, Abdolmajid Safarzaei ${ }^{4}$
}

'Department of Horticultural Science, Science and Research Branch, Islamic Azad University, Tehran, Iran ${ }^{2}$ Department of Plant Breeding and Biotechnology, Faculty of Agriculture, University of Zabol, Zabol, Iran

${ }^{3}$ Department of Plant Production, College of Agriculture and Natural Resources of Darab, Shiraz University, Darab, Fars, Iran ${ }^{4}$ Zabol University of Medical Sciences, Zabol, Iran

\author{
*Correspondence to \\ Mahmood Solouki, \\ Email: \\ mahmood.solouki@gmail.com
}

Received January 8, 2018

Accepted September 19, 2019

Published online September 30, 2019

\begin{abstract}
Introduction: Moringa peregrina (Forssk.) Fiori, is a nutritionally and medicinally important desert tree, which is constantly exposed to drought stress. This study was accomplished to alleviate the adverse effects of drought stress on $M$. peregrina populations through the foliar application of zinc oxide nanoparticles (ZnO-NPs) by monitoring some physiological and biochemical alterations.

Methods: Moringa peregrina seeds were collected from the Southeast of Iran in 2014. Fourteen days after germination, the seedlings were subjected to drought stress by withholding watering until $50 \%$ field capacity (FC), followed by spraying $0.1 \%$ and $0.05 \%$ ZnO-NPs and no spraying (as control).

Results: The changes of sodium ( $\mathrm{Na})$, potassium $(\mathrm{K})$, chlorophylls, total phenolic content (TPC) as well as antioxidant activity under drought stress condition varied based on M. peregrina populations. Drought stress significantly reduced chlorophylls content, while it enhanced TPC and antioxidant activity. ZnO-NPs treatment significantly inhibited chlorophylls degradation under drought stress conditions. It also enhanced chlorophyll content in well-watered plants. Moreover, it was revealed that TPC and antioxidant activity of $M$. peregrina populations significantly increased in response to foliar application of ZnO-NPs in both drought-stressed and unstressed plants.

Conclusion: Our results suggested that ZnO-NPs spray can augment drought tolerance of different populations of M. peregrina subjected to water deficit condition.

Keywords: Chlorophylls, Nutrients uptake, Phenol, Secondary metabolites, ZnO-NPs
\end{abstract}

\section{Introduction}

Moringa is a small genus from the family of Moringaceae, consisting of 13 species from subtropical to tropical regions and ranging in size from small herbs to large trees. The Moringa trees are important food commodities as almost all plant parts such as fruits, flowers, leaves, and immature pods can be consumed as highly nutritive vegetables. ${ }^{1}$ Moringa peregrine (Forssk.) Fiori, which is commonly known as horseradish tree, has economical and medicinal importance. The pharmacological actions were attributed to the presence of phenolic compounds in its leaf extract. It was revealed that the leaves of $M$. peregrina are rich sources
\end{abstract}

of vitamins, minerals, proteins, and phenolic compounds. It acts as a good source of natural antioxidants and also plays an important role in preventing and progression of many diseases. ${ }^{2} M$. peregrina can be grown on arid and semiarid areas with high temperatures and low water availability where cultivation of other agricultural crops is difficult due to drought stress. ${ }^{3}$

Drought stress is one of the most serious abiotic stresses that limit plant growth. Numerous changes have been observed in plants as a result of water stress such as changes in mineral nutrients balance, bioactive compounds, and antioxidant activity. These changes depend on species,

(c) 2019 The Author(s); Published by Zabol University of Medical Sciences. This is an open-access article distributed under the terms of the Creative Commons Attribution License (http://creativecommons.org/licenses/by/4.0), which permits unrestricted use, distribution, and reproduction in any medium, provided the original work is properly cited. 
genotypes, severity, duration, and time course of drought stress. ${ }^{4}$ Nowadays, the cultivation of medicinal plants is done in a drought stress condition to influence the secondary metabolites content such as phenols. ${ }^{5}$

Phenolic compounds as the largest groups of phytochemicals are present in foods. Flavonoids and other phenolic compounds are potent antioxidants and anticarcinogenic agents. Polyphenols exist in many plants and are especially abundant in the Moringa tree, whose dried leaves are used as antioxidant. ${ }^{6}$ Drought can also lead to pigment degradation, thus causing irreversible water-deficit damage to the photosynthetic apparatus. One of the indicators of the stress tolerance capacity of plants is chlorophyll stability index. ${ }^{7}$ In addition, it has been demonstrated that antioxidants affect the chlorophyll content of plants as well. ${ }^{8}$

The tolerance of plants to environmental stresses such as water deficit can be fortified by micronutrient fertilizers. Zinc $(\mathrm{Zn})$ is an essential micronutrient required for metabolic activity, water balance, and stomatal regulation in plants. It adjusts various enzymatic functions and is required for biochemical reactions resulting in chlorophyll formation. ${ }^{9}$ Currently, the use of nano-materials such as zinc oxide nanoparticles ( $\mathrm{ZnO}-\mathrm{NPs}$ ) has been expanded. ${ }^{10}$

It has been demonstrated that the use of micronutrient fertilizers in the form of NPs is an appropriate procedure to release required nutrients gradually and in a controlled way, which is essential to mitigate the problems of fertilizer pollutions. Due to high surface-to-volume ratio, highly active surface, unique size and shape, and physical, chemical, biological, and catalytic properties, NPs can modulate chemical and biological activities of cells. ${ }^{11}$ It has been reported that $\mathrm{ZnO}-\mathrm{NPs}$ can produce better results than the conventional $\mathrm{ZnO} .^{10}$ Additionally, $\mathrm{ZnO}$ NPs possess excellent electrical properties. ${ }^{12}$

However, to the best of our knowledge, there is little or no reliable information about the physiological effects of foliar application of $\mathrm{ZnO}$-NPs on mineral and biochemical content of medicinal plants under well-watered as well as drought stress conditions. Therefore, this study was carried out to evaluate the changes of mineral nutrients, chlorophylls as well as phenolic compounds, and antioxidant activity of different $M$. peregrina populations under well-watered and drought stress conditions in response to foliar application of $\mathrm{ZnO}-\mathrm{NPs}$.

\section{Materials and Methods}

Plant Materials and Growth Conditions

The experiment was conducted in a greenhouse at the Faculty of Agriculture, University of Sistan and Baluchestan, Zahedan, Iran (latitude of $29^{\circ} 27^{\prime} 34^{\prime \prime} \mathrm{N}$, longitude of $60^{\circ} 51^{\prime} 10^{\prime \prime} \mathrm{E}, 1385 \mathrm{~m}$ altitude, mean annual temperature of $18.3^{\circ} \mathrm{C}$ and rainfall of $72 \mathrm{~mm}$ ), during the 2014 growing season. Ten populations of $M$. peregrine seeds were collected from different regions of Sistan and Baluchestan province, Southeast of Iran. The seeds were cleaned to remove damaged seeds, stones, leaves, wood, dust, and any other unknown materials. Cleaned seeds were stored in black plastic bags and labeled. The locations of all samples have been shown in Table 1. The regions where the populations were located are typically characterized by an arid and semi-arid climate.

Seeds were surface-sterilized with $0.5 \%(\mathrm{v} / \mathrm{v})$ sodium hypochlorite and treated with benomyl solution for 30 minutes at $24^{\circ} \mathrm{C}$ and then washed three times with sterilized deionized water. Twenty seeds were placed in each 9-cm Petri dish on two sheets of filter paper moistened. The seeds were kept in a germination chamber under a photoperiod of 12 hours at $25^{\circ} \mathrm{C}$. After germination, the seedlings were kept in a growth chamber for 14 days at $25^{\circ} \mathrm{C}, 70 \%$ relative humidity with a 12 -hour photoperiod and watered daily. Later, the young plants were sown in plastic pots $(30 \mathrm{~cm}$ height and $20 \mathrm{~cm}$ diameter) filled with steam-sterilized soil containing washed sand (3:1:1, $\mathrm{v} / \mathrm{v} / \mathrm{v}$ ), clay horizon (red earth), and organic horizon soil (black soil). They were fully randomized, kept in a greenhouse and watered daily. Young plants, 40 days after germination, were exposed to drought stress and $\mathrm{ZnO}$ NPs treatment.

\section{Treatments}

The field capacity (FC) of the medium in the pot was measured prior to each treatment. Three pots were saturated with water, covered with plastic to avoid

Table 1. The Geographical Location of Moringa peregrine Populations in Sistan and Baluchestan Province, Iran

\begin{tabular}{|c|c|c|c|c|}
\hline Population Number & Positions & Location of Collected & Latitude & Longitude \\
\hline 1 & Nikshahr & Konardan & $29^{\circ} 16^{\prime} 69^{\prime \prime} \mathrm{N}$ & $21^{\circ} 79^{\prime} 56^{\prime \prime} \mathrm{E}$ \\
\hline 2 & Nikshahr & Keshik & $29^{\circ} 13^{\prime} 84^{\prime \prime} \mathrm{N}$ & $23^{\circ} 27^{\prime} 94^{\prime \prime} \mathrm{E}$ \\
\hline 3 & Nikshahr & Shegim & $29^{\circ} 29^{\prime} 04^{\prime \prime} \mathrm{N}$ & $21^{\circ} 87^{\prime} 17^{\prime \prime} \mathrm{E}$ \\
\hline 4 & Nikshahr & Desk & $29^{\circ} 17^{\prime} 75^{\prime \prime} \mathrm{N}$ & $21^{\circ} 92^{\prime} 40^{\prime \prime} \mathrm{E}$ \\
\hline 5 & Nikshahr & Nesfuran & $29^{\circ} 18^{\prime} 55^{\prime \prime} \mathrm{N}$ & $78^{\circ} 40^{\prime} 95^{\prime \prime} \mathrm{E}$ \\
\hline 6 & Fanuj & Girls Seven & $29^{\circ} 19^{\prime} 72^{\prime \prime} \mathrm{N}$ & $75^{\circ} 26^{\prime} 06^{\prime \prime} \mathrm{E}$ \\
\hline 7 & Fanuj & Tange Fanuj Entrance & $29^{\circ} 38^{\prime} 89^{\prime \prime} \mathrm{N}$ & $76^{\circ} 27^{\prime} 30^{\prime \prime} \mathrm{E}$ \\
\hline 8 & Fanuj & Tange Fanuj & $29^{\circ} 35^{\prime} 68^{\prime \prime} \mathrm{N}$ & $76^{\circ} 29^{\prime} 73^{\prime \prime} \mathrm{E}$ \\
\hline 9 & Fanuj & Madohi village & $29^{\circ} 29^{\prime} 45^{\prime \prime} \mathrm{N}$ & $76^{\circ} 26^{\prime} 47^{\prime \prime} \mathrm{E}$ \\
\hline 10 & Fanuj & Dahan village & $29^{\circ} 15^{\prime} 45^{\prime \prime} \mathrm{N}$ & $75^{\circ} 39^{\prime} 26^{\prime \prime} \mathrm{E}$ \\
\hline
\end{tabular}


evaporation and allowed to drain for 24 hours. The moisture content was determined after soil sampling from each pot. Average moisture content was calculated according to Kramer and Boyer. ${ }^{13}$ The performance of drought stress was evaluated at 40 days after germination. All the pots were maintained at $100 \%$ FC (well-watered) and $50 \%$ FC (drought stress) during the period of treatment.

At 7 days after drought stress, plants were sprayed with the different concentration of $\mathrm{ZnO}-\mathrm{NPs}$ [0 (as control), 0.05 , and $0.1 \%]$. The second foliar application of $\mathrm{ZnO}$ NPs was carried out one week later. Plants were sprayed until the leaves were completely wet and the solution ran off the leaves. The $\mathrm{ZnO}$-NPs was purchased from Iranian Nanomaterials Pioneers Company, Iran. Plants were harvested at 30 days after $\mathrm{ZnO}$-NPs spraying and were further processed for proximate analysis.

Sodium and Potassium Content

Before the measurement of $\mathrm{Na}^{+}$and $\mathrm{K}^{+}$, leaf samples were exactly washed by tap water and then rinsed with deionized water to remove all surface remnants. Fruit flesh samples, after air-drying, were taken from the equatorial section of each fruit quarter, oven-dried at $70^{\circ} \mathrm{C}$ for 48 hours and milled to pass through a 40-mesh sieve. A portion of fine powder weighing $2 \mathrm{~g}$ was dry washed in a furnace at $550^{\circ} \mathrm{C}$ for 4 hours and then the ash was dissolved in $10 \mathrm{~mL}$ of $2 \mathrm{M}$ hydrochloric acid ( $\mathrm{HCl})$. Through a Whatman No. 40 filter paper, the digested samples were filtered and used for the analysis of $\mathrm{Na}^{+}$and $\mathrm{K}^{+} . \mathrm{Na}^{+}$and $\mathrm{K}^{+}$content was determined by flame photometric (Biotech Engineering Management Co. Ltd., UK) method as already described. ${ }^{14}$

\section{Chlorophyll Assay}

The content of chlorophyll a (Chl-a), chlorophyll b (Chl-b), and total chlorophyll (T-Chl) was determined by UV-visible spectrophotometry (PG Instrument Ltd., Leicester, UK) as described by Rajalakshmi and Banu. ${ }^{15}$ Briefly, $10 \mathrm{~mL}$ of acetone $80 \%$ was added to 0.1 $\mathrm{g}$ of homogenized freeze-dried herbage samples. The samples were centrifuged at $6000 \mathrm{~g}$ for 10 minutes. The supernatant was filtered through a Whatman No.1 filter paper and the absorbances were read at 645 and $663 \mathrm{~nm}$ using UV-visible spectrophotometer. The amounts of Chl-a, Chl-b and T-Chl were calculated according to the following formulas:

Chl-a $=\left[\left(19.3 \times \mathrm{A}_{663}-0.86 \times \mathrm{A}_{645}\right) \times \mathrm{V}\right] / 100 \mathrm{~W}$

Chl-b $=\left[\left(19.3 \times \mathrm{A}_{645}-3.6 \times \mathrm{A}_{663}\right) \times \mathrm{V}\right] / 100 \mathrm{~W}$

$\mathrm{T}-\mathrm{Chl}=\mathrm{Chl}-\mathrm{a}+\mathrm{Chl}-\mathrm{b}$

Where $\mathrm{A}_{645}$ and $\mathrm{A}_{663}$ are the absorbances at 645 and 663 $\mathrm{nm}$, "V" is sample volume in absorbance, and "W" is the fresh weight (FW) of sample in grams.

Total Phenol Content

The total phenolic content (TPC) was determined using
Folin-Ciocalteu method with minor modifications. ${ }^{16}$ TPC extraction was carried out by $10 \mathrm{~mL}$ acidic methanol added to $1 \mathrm{~g}$ of the leaf powder with the mixture and then filtered through ordinary filter paper. Afterwards, $500 \mu \mathrm{L}$ of this extract was diluted with $5 \mathrm{~mL}$ of Folin-Ciocalteu reagent $\left(1: 10 \mathrm{~g} \mathrm{~mL}^{-1}\right)$, and then $4 \mathrm{~mL}$ of $\mathrm{Na}_{2} \mathrm{CO}_{3}(1 \mathrm{M})$ was added to the mixture. This reaction solution was shaken in a shaker and kept in dark for 15 minutes. The absorbance of samples was taken at $765 \mathrm{~nm}$ using UV/ Visible spectrophotometer (model PG Instrument +80 , Leicester, UK). Gallic acid was used as standard to obtain calibration curve. Data were expressed as milligram gallic acid equivalent (mg GAE) per $1 \mathrm{~g}$ of fruit FW.

\section{Antioxidant Activity}

The antioxidant activity was evaluated by 2, 2-diphenyl-1picrylhydrazyl (DPPH) free radical-scavenging method with some modifications. ${ }^{16}$ The absorbance of the samples was measured at $515 \mathrm{~nm}$ and the antioxidant activity was expressed as the percentage of the decline of the absorbance, relative to the control, corresponding to the percentage of DPPH that was scavenged. The percentage of DPPH, which was scavenged (\%DPPHsc), was calculated using:

$\% \mathrm{DPPHsc}=\left[\left(\mathrm{A}_{\text {cont }}-\mathrm{A}_{\text {samp }}\right) / \mathrm{A}_{\text {cont }}\right] \times 100$

Where $\mathrm{A}_{\text {cont }}$ is the absorbance of the control, and $\mathrm{A}_{\text {samp }}$ is the absorbance of the sample.

Statistical Analysis

The experiments were carried out according to a 3-factor linear model based on a completely randomized design with three replications. Data were statistically analyzed using analysis of variance (ANOVA) by SAS software (version 9.1 2002-2003, SAS Institute, Cary, NC, USA). Before analysis of variance, data were tested for normality and homoscedasticity using the Shapiro-Wilk test. Least significant difference (LSD) test at $P \leq 0.01$ probability level was considered as the statistical significance level.

\section{Results}

Minerals Content

The results showed that drought stress reduced $\mathrm{Na}^{+}$ and $\mathrm{K}^{+}$content in all $M$. peregrina populations (Table 2). The highest $\mathrm{Na}$ and $\mathrm{K}$ contents were found at $50 \%$ FC in population number 7 (0.89 and $13.69 \mathrm{mg} \mathrm{g}^{-1} \mathrm{DW}$, respectively). Under well-watered conditions, untreated plants (controls) had higher $\mathrm{Na}$ content, whereas under drought conditions, $\mathrm{ZnO}$-NPs treatment slightly enhanced Na content compared with control (Figure 1). However, it was revealed that the interaction effects of drought stress and $\mathrm{ZnO}$-NPs treatment on the $\mathrm{K}$ content of $M$. peregrina populations were not significant $(P \leq 0.01)$ according to the LSD test (Figure 2).

Chlorophylls Content 


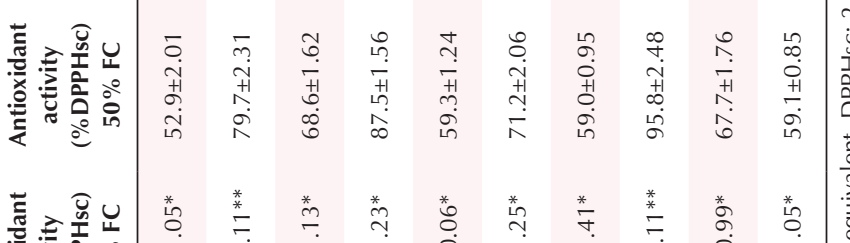

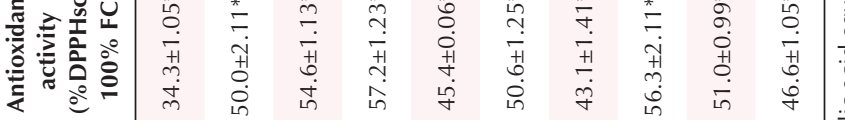

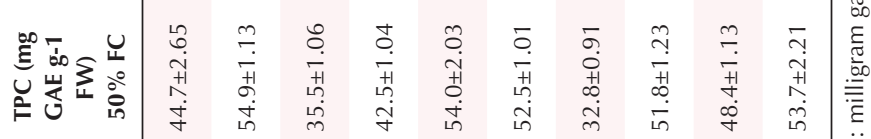

宸崩

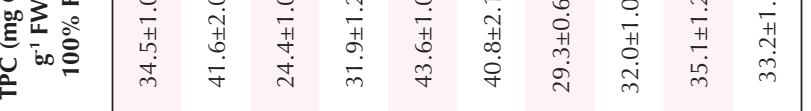

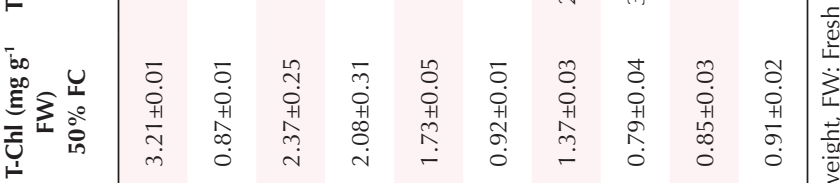

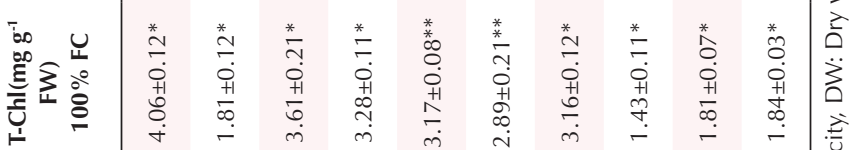

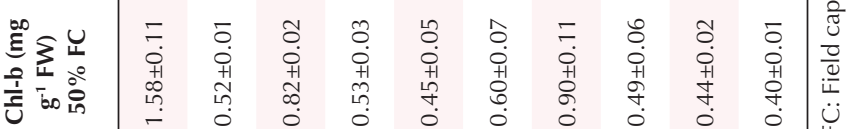

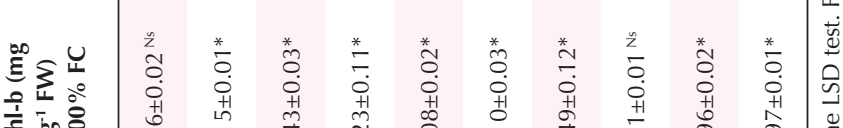

宅的空

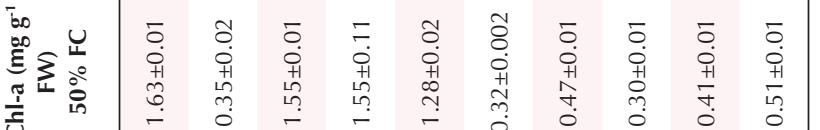

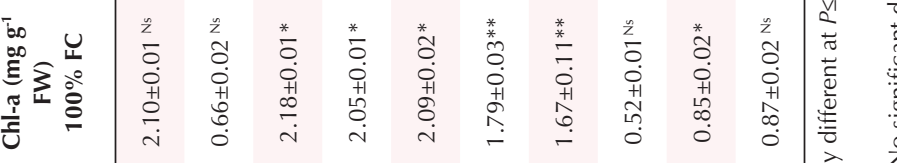

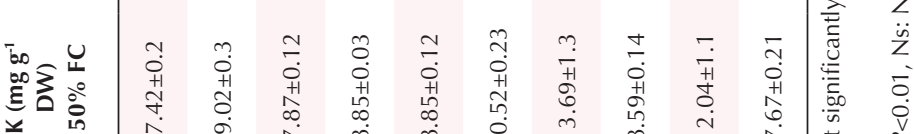

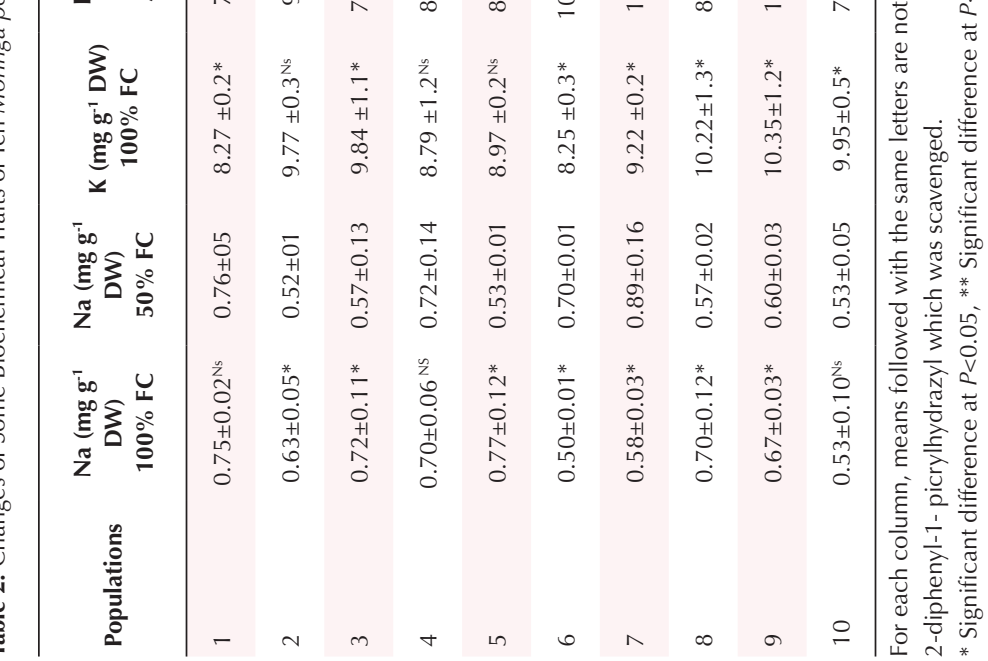




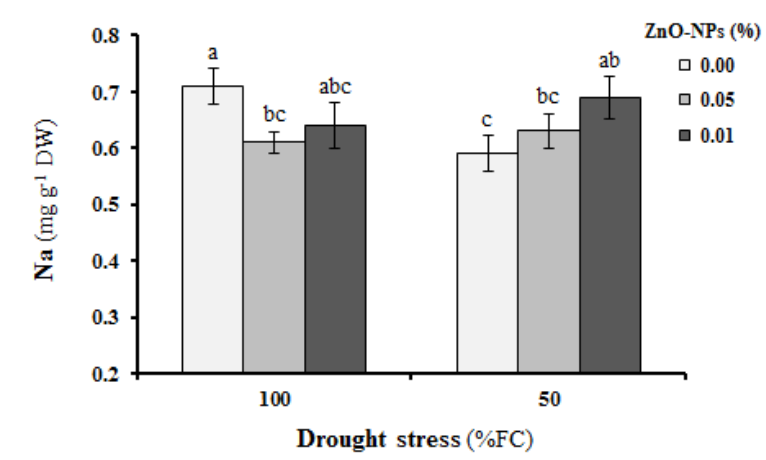

Figure 1. The Effect of Zinc Oxide Nanoparticles (ZnO-NPs) Treatment on the Na Content of $M$. peregrina Under Well-Watered (100\% FC) and Drought Stress $(50 \%$ FC) Conditions. The values are shown as the means $(n=3) \pm$ standard error. Different letters indicate significant difference $(P \leq 0.01)$ according to the LSD test. FC: Field capacity, DW: Dry weight.

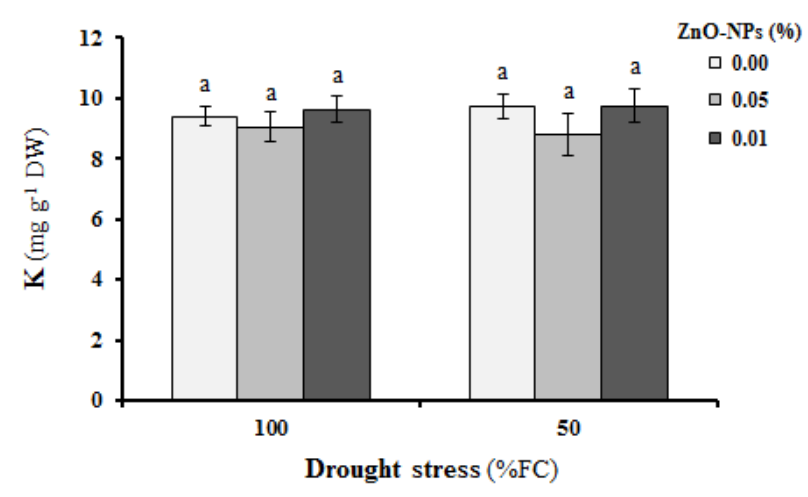

Figure 2. The Effect of Zinc Oxide Nanoparticles (ZnO-NPs) Treatment on the K Content of M. peregrina Under Well-Watered (100\% FC) and Drought Stress $(50 \%$ FC) Conditions. The values are shown as the means $(n=3) \pm$ standard error. Different letters indicate significant difference $(P \leq 0.01)$ according to the LSD test. FC: Field capacity, DW: Dry weight.
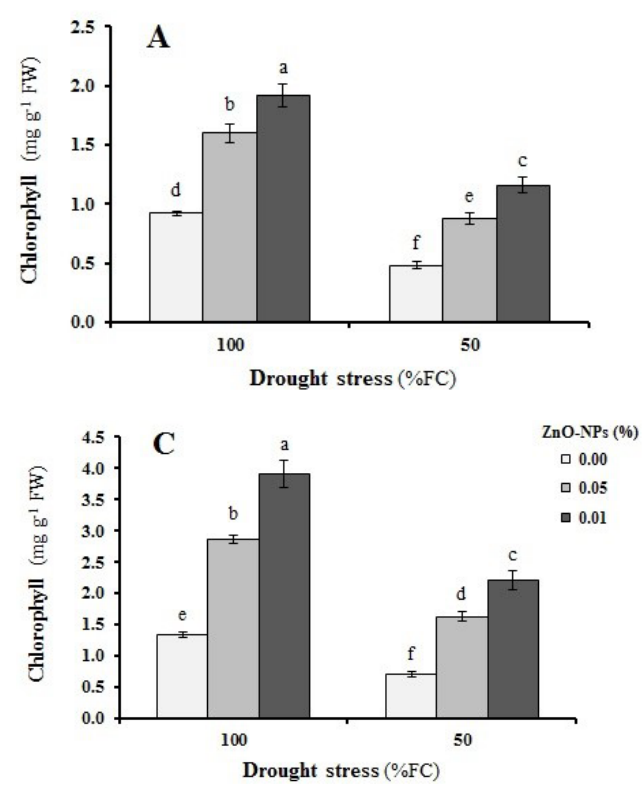

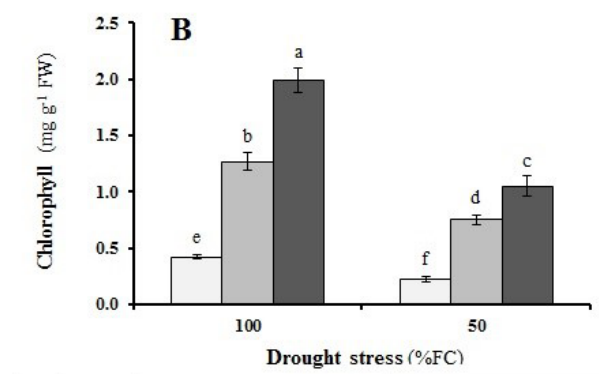

Chlorophylls content significantly differed in various $M$. peregrina populations, and population number 1 had the highest $\mathrm{T}$-Chl content $\left(4.06 \mathrm{mg} \mathrm{g}^{-1} \mathrm{FW}\right)$ under wellwatered condition. In addition, drought stress significantly reduced chlorophyll content, as compared with others. The population number 1 had the highest T-Chl content (3.21 $\mathrm{mg} \mathrm{g}^{-1} \mathrm{FW}$ ) in drought stress condition (Table 2). Our results showed that foliar spray of $\mathrm{ZnO}-\mathrm{NPs}$ not only prevented chlorophylls degradation but also significantly enhanced Chl-a, Chl-b as well as T-Chl content in both drought-stressed and unstressed plants. The $0.10 \% \mathrm{ZnO}$ NPs concentration was most effective in enhancing chlorophylls content (Figure 3).

Total Phenol Content

In well-watered plants, TPC varied from 24.4 to $43.6 \mathrm{mg}$ GAE $\mathrm{g}^{-1} \mathrm{FW}$ depending on $M$. peregrina populations. Furthermore, TPC significantly increased in response to drought stress (Table 2). Under both well-watered and drought conditions, foliar application of $\mathrm{ZnO}$-NPs significantly increased TPC (Figure 4). The highest TPC was obtained in stressed plants that were treated with 0.05\% ZnO-NPs (81.37 $\left.\mathrm{mg} \mathrm{GAE} \mathrm{g}^{-1} \mathrm{FW}\right)$.

\section{Antioxidant Activity}

In well-watered conditions, population number 4 and 8 had the highest antioxidant activity (57.2 and $56.8 \%$ DPPHsc, respectively). The antioxidant activity of $M$. peregrina populations significantly increased under drought stress, and the highest antioxidant activity was observed in population number 8 and 4 (95.8 and 87.5 $\%$ DPPHsc, respectively). Similar pattern was found in both drought-stressed and unstressed plants in response

Figure 2. The Effect of Zinc Oxide Nanoparticles (ZnO-NPs) Treatment on the K Content of M. peregrina Under Well-Watered (100\% FC) and Drought Stress $(50 \%$ FC) Conditions. The values are shown as the means $(n=3) \pm$ standard error. Different letters indicate significant difference $(P \leq 0.01)$ according to the LSD test. FC: Field capacity, DW: Dry weight. 


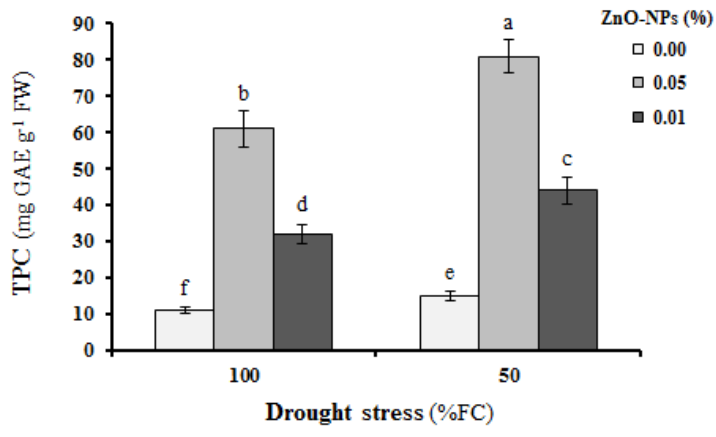

Figure 4. The Effect of Zinc Oxide Nanoparticles (ZnO-NPs) Treatment on the Total Phenol Content (TPC) of M. peregrina Under Well-Watered (100\% FC) and Drought Stress (50\% FC) Conditions. The values are shown as the means $(n=3) \pm$ standard error. Different letters indicate significant difference $(P \leq 0.01)$ according to the LSD test. FC: Field capacity, mg GAE: milligram gallic acid equivalent.

to foliar application of $\mathrm{ZnO}-\mathrm{NPs}$ (Figure 5). $\mathrm{ZnO}-\mathrm{NPs}$ treatment significantly enhanced the antioxidant activity of $M$. peregrina populations as compared with untreated ones. The antioxidant activity significantly increased at $0.05 \% \mathrm{ZnO}-\mathrm{NPs}$ and then reduced at $0.10 \% \mathrm{ZnO}-\mathrm{NPs}$, while it was still higher compared to control plants. The highest antioxidant activity (82.1\% DPPHsc) of $M$. peregrina was obtained under drought stress conditions in plants treated with $0.05 \% \mathrm{ZnO}-\mathrm{NPs}$.

\section{Discussion}

The present study has revealed that $\mathrm{ZnO}$-NPs spray can increase the tolerance of $M$. peregrina plant to drought stress by enhancing some secondary metabolites and antioxidant potential. Drought stress affects the minerals uptake by plant roots through influencing root growth and nutrient mobility in soil. Under drought stress, water availability is reduced, followed generally by reduction in total nutrient uptake and the concentrations of minerals in crops. ${ }^{17}$ The most important effect of drought stress is observed on the transport of nutrients to the root which affects root growth and extension. The content of nutrient elements is balanced by nutrient uptake and unloading mechanisms as well as transpiration flow. ${ }^{18}$ It has been revealed that drought stress significantly reduced $\mathrm{Na}$ and enhanced $\mathrm{K}$ uptake and ion uptake efficiency in different chickpea genotypes. ${ }^{19}$

According to our results, drought stress reduced $\mathrm{Na}^{+}$ and $\mathrm{K}^{+}$content in all $M$. peregrina populations. However, under drought conditions, $\mathrm{ZnO}$-NPs treatment increased $\mathrm{Na}^{+}$content. Change in nutrients balance in response to $\mathrm{Zn}$-NPs spray is in agreement with the findings of Soliman et $\mathrm{al}^{20}$ who reported that foliar application of Zn-NPs significantly affects mineral nutrients content of $M$. peregrina. $\mathrm{Zn}$ seems to affect the capacity for water and nutrients uptake as well as transport in plants under different abiotic stresses. ${ }^{21}$ Our results revealed that Zn-NPs spray enhanced $\mathrm{Na}$ content in drought stress conditions, which was in agreement with the findings

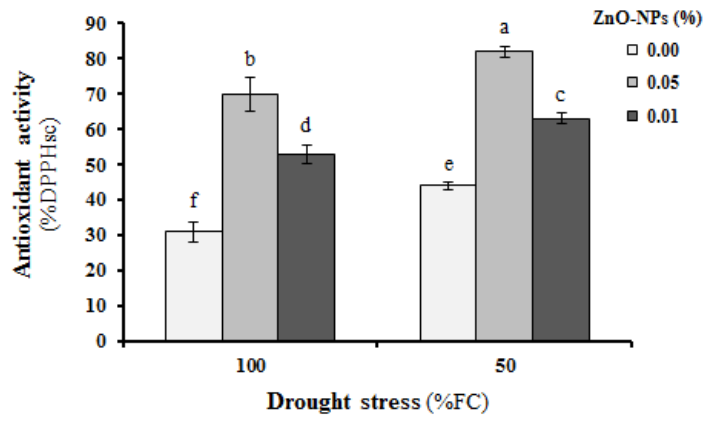

Figure 5. The Effect of Zinc Oxide Nanoparticles (ZnO-NPs) Treatment on the Antioxidant Activity of M. peregrina Under Well-Watered (100\% FC) and Drought Stress (50\% FC) Conditions. The values are shown as the means $(\mathrm{n}=3) \pm$ standard error. Different letters indicate significant difference $(P \leq 0.01)$ according to the LSD test. FC: Field capacity, DPPHsc: 2, 2-diphenyl-1picrylhydrazyl which was scavenged.

of Martinez et $\mathrm{al},{ }^{22}$ who reported that plant tolerances to water deficit is due to a common mechanism of Na uptake for osmotic adjustment.

Our results showed that foliar spray of $\mathrm{ZnO}-\mathrm{NPs}$ not only prevented chlorophylls degradation but also significantly enhanced Chl-a, Chl-b as well as T-Chl content in both drought-stressed and unstressed plants. Photosynthetic pigments control the energy balance through chlorophylls and therefore, they involve in the adaptation and survival of plants in drought. ${ }^{23}$ Inhibition of chlorophyll biosynthesis, activation of chlorophyllase and/or destruction of chloroplast structure lowered the pigment content under abiotic stress conditions. ${ }^{20}$ In addition, Mejri et $\mathrm{al}^{24}$ reported that drought stress prevented from chloroplast activity and led to the breakdown of chlorophyll as well as changes in chlorophyll a to $b$ ratio. It has been reported that the decrease in chlorophyll under drought stress is generally the consequence of chloroplast damages resulting from reactive oxygen species (ROS) ${ }^{25}$ Another reason for the decline in chlorophyll is the application of a glutamate precursor for the biosynthesis of proline. ${ }^{26}$

Enhancing chlorophylls content by ZnO-NPs treatment are in agreement with the results obtained by Fathi et $\mathrm{al}^{27}$ and Kheirizadeh Arough et $\mathrm{al}^{28}$ who mentioned that ZnO-NPs treated plants showed higher amount of total chlorophyll content than the control. Moreover, Sharma et $\mathrm{al}^{29}$ reported that $\mathrm{Zn}$ treatment increased the growth of cabbage and improved the chlorophyll content and photosynthetic activity in the leaves. Zarrouk et $\mathrm{al}^{30}$ showed a positive correlation between $\mathrm{Zn}$ concentrations and leaf chlorophyll content in plants. It has been demonstrated that $\mathrm{ZnO}$ NPs induced the expression of chlorophyll synthesis genes. ${ }^{31}$

Based on the present study, TPC increased in response to drought stress. However, foliar application of $\mathrm{ZnO}$ NPs increased TPC under both well-watered and drought conditions. The increase in TPC under drought stress condition is due to the soluble carbohydrates accumulation 
in plant cells because transportation of soluble sugars is reduced under water deficit. ${ }^{32}$ Phenolic compounds are biosynthesized through various mechanisms such as malonic acid and shikimic acid pathways. Simple carbohydrate precursors are converted into aromatic amino acids through shikimic acid pathway. ${ }^{33}$ It has been reported that the increase of phenolic compounds is highly correlated with the balance between carbohydrate sources and sinks. ${ }^{32,34}$ Moreover, the TPC enhancement under drought stress is greatly related to the production and distribution of various antioxidants in the plant and the intensity and duration of stress. ${ }^{35}$ Similarly, we found that there was a significant positive correlation between TPC and antioxidant activity $(r=0.93)$. The increase of TPC by foliar application of $\mathrm{ZnO}-\mathrm{NPs}$ is in agreement with findings of Oloumi et $\mathrm{al}^{36}$ who mentioned that the phenolic compounds contents in seedlings of Glycyrrhiza glabra L. significantly increased in response to $10 \mu \mathrm{M}$ $\mathrm{ZnO}$-NPs. They suggested that it might be due to the ability of ZnO-NPs to affect metabolic activity.

In the present study, the antioxidant activity of $M$. peregrina populations remarkably increased under drought stress. Drought stress, at the cellular level, induces the accumulation of ROS such as superoxide radicals, hydrogen peroxide, and hydroxyl radicals. The excess ROS are detrimental because they damage membranes, proteins, chlorophylls and nucleic acids. To reduce this oxidative damage, plants enhance their antioxidant defense systems including enzymatic and non-enzymatic scavenging mechanisms. ${ }^{23}$ The antioxidant activity has a crucial role in maintaining the balance between the production and scavenging of free radicals, therefore, the number of antioxidants should be high to compensate and tolerate stress condition. ${ }^{32}$

Our results indicated that $\mathrm{ZnO}-\mathrm{NPs}$ treatment enhanced the antioxidant activity of $M$. peregrina populations as compared with untreated ones. It was revealed that the application of $\mathrm{Zn}$ under abiotic stress enhanced removing reactive oxygen species by increasing antioxidant enzymes activities. Zn ions bind to ligands containing sulfur, nitrogen, and to a lesser extent oxygen, and preferentially bind to the membrane proteins. ${ }^{28}$ Our results are in agreement with the findings of Tavallali et $\mathrm{al}^{37}$ who reported that $\mathrm{Zn}$ is able to facilitate the biosynthesis of antioxidant enzymes and enhance antioxidant activity in the leaves of pistachio under abiotic stress conditions. The balance between the generation and removal of free radicals determines the survival of the system. Therefore, $\mathrm{Zn}$ may have a role in modulating free radicals and their related damaging effects by enhancing the antioxidant activity of plants. ${ }^{38}$

The antioxidant property of $\mathrm{ZnO}-\mathrm{NPs}$ could be resulted from the transfer of electron density located at oxygen to the odd electron located at nitrogen atom in DPPH. ${ }^{39}$ This characteristic is dependent on the structural configuration of oxygen atom, and it determines the thermal stability of nanoparticle. ${ }^{40}$ In addition, the antioxidant efficacy of $\mathrm{ZnO}-\mathrm{NPs}$ against DPPH is likely due to the electrostatic attraction between positively charged NPs $\left(\mathrm{ZnO}=\mathrm{Zn}^{2+}+\mathrm{O}^{2}\right)$ of plant extracts and negatively charged bioactive compounds $\left(\mathrm{COO}^{-}, \mathrm{O}^{-}\right){ }^{41}$ Binding of $\mathrm{ZnO}-\mathrm{NPs}$ to phytochemicals synergistically increase their bioactivity. ${ }^{42}$

\section{Conclusion}

$\mathrm{ZnO}$-NPs treatment effectively protected $M$. peregrina populations from drought stress by inhibiting the chlorophylls degradation and enhancing TCP and antioxidant activity. Hence, foliar application of $\mathrm{ZnO}-\mathrm{NPs}$ is recommended for the growth of different $M$. peregrina populations under drought stress conditions.

\section{Competing Interests}

The authors declare that they have no competing financial, professional, or personal interests that might have influenced the performance or presentation of the study described in this manuscript.

\section{Ethical Approval}

Not applicable.

\section{Acknowledgment}

The authors would like to thank the Science and Research Branch, Islamic Azad University, Tehran, Iran, and University of Zabol, Zabol, Iran, for funding this research.

\section{References}

1. Alaklabi A. Genetic diversity of Moringa peregrina species in Saudi Arabia with ITS sequences. Saudi J Biol Sci. 2015;22(2):186-190. doi:10.1016/j.sjbs.2014.09.015

2. Al-Owaisi M, Al-Hadiwi N, Khan SA. GC-MS analysis, determination of total phenolics, flavonoid content and free radical scavenging activities of various crude extracts of Moringa peregrina (Forssk.) Fiori leaves. Asian Pac J Trop Biomed. 2014;4(12):964-970. doi:10.12980/ APJTB.4.201414B295

3. Salaheldeen M, Aroua MK, Mariod AA, Cheng SF, Abdelrahman MA. An evaluation of Moringa peregrina seeds as a source for bio-fuel. Ind Crops Prod. 2014;61:4961. doi:10.1016/j.indcrop.2014.06.027

4. Imadi SR, Gul A, Dikilitas M, Karakas S, Sharma I, Ahmad P. Water stress: types, causes, and impact on plant growth and development. In: Ahmad P, ed. Water Stress and Crop Plants. Chichester, UK: John Wiley \& Sons, Ltd; 2016:343355. doi: 10.1002/9781119054450.ch21.

5. Wu X, Yuan J, Luo A, Chen Y, Fan Y. Drought stress and re-watering increase secondary metabolites and enzyme activity in dendrobium moniliforme. Ind Crops Prod. 2016;94:385-393. doi:10.1016/j.indcrop.2016.08.041

6. Koheil MA, Hussein MA, Othman SM, El-Haddad A. Anti-inflammatory and antioxidant activities of Moringa peregrina Seeds. Free Radicals and Antioxidants. 2011;1(2):49-61. doi:10.5530/ax.2011.2.10

7. Terzi R, Kadioğlu A. Drought stress tolerance and the 
antioxidant enzyme system in Ctenanthe setosa. Acta Biol Crac Ser Bot. 2006;48(2):89-96.

8. Lanfer-Marquez UM, Barros RMC, Sinnecker P. Antioxidant activity of chlorophylls and their derivatives. Food Res Int. 2005;38(8-9):885-891. doi:10.1016/j. foodres.2005.02.012

9. Kisan B, Shruthi H, Sharanagouda H, Revanappa SB, Pramod NK. Effect of nano-zinc oxide on the leaf physical and nutritional quality of spinach. Agrotechnology. 2015;5(1):135. doi:10.4172/2168-9881.1000135

10. Swain PS, Rao SBN, Rajendran D, Dominic G, Selvaraju S. Nano zinc, an alternative to conventional zinc as animal feed supplement: a review. Anim Nutr. 2016;2(3):134-141. doi:10.1016/j.aninu.2016.06.003

11. Laware SL, Raskar S. Influence of zinc oxide nanoparticles on growth, flowering and seed productivity in onion. Int J Curr Microbiol Appl Sci. 2014;3(7):874-881.

12. Perumal V, Hashim U, Gopinath SCB, et al. A new nanoworm structure from gold-nanoparticle mediated random curving of zinc oxide nanorods. Biosens Bioelectron. 2016;78:14-22. doi:10.1016/j.bios.2015.10.083

13. Kramer PJ, Boyer JS. Water relations of plants and soils. San Diego, CA, USA: Academic Press; 1995:495.

14. Walinga I, van Vark W, Houba VJG, van der lee JJ. Soil and plant analysis: a series of syllabi. Wageningen Agricultural University; 1989.

15. Rajalakshmi K, Banu N. Extraction and estimation of chlorophyll from medicinal plants. Int J Sci Res. 2015;4(11):209-212.

16. McDonald S, Prenzler PD, Antolovich M, Robards K. Phenolic content and antioxidant activity of olive extracts. Food Chem. 2001;73(1):73-84. doi:10.1016/S03088146(00)00288-0

17. Gunes A, Cicek N, Inal A, et al. Genotypic response of chickpea (Cicer arietinum L.) cultivars to drought stress implemented at pre-and post-anthesis stages and its relations with nutrient uptake and efficiency. Plant Soil Environ. 2006;52(8):368-376. doi:10.17221/3454-PSE

18. Bista DR, Heckathorn SA, Jayawardena DM, Mishra S, Boldt JK. Effects of drought on nutrient uptake and the levels of nutrient-uptake proteins in roots of droughtsensitive and-tolerant grasses. Plants (Basel). 2018;7(2). doi:10.3390/plants7020028

19. Talebi R, Ensafi MH, Baghebani N, Karami E, Mohammadi K. Physiological responses of chickpea (Cicer arietinum) genotypes to drought stress. Environ Exp Biol. 2013;11:915.

20. Soliman AS, El-feky SA, Darwish E. Alleviation of salt stress on Moringa peregrina using foliar application of nanofertilizers. J Hortic For. 2015;7(2):36-47. doi:10.5897/ JHF2014.0379

21. Hafeez B, Khanif YM, Saleem M. Role of zinc in plant nutrition-a review. Am J Exp Agric. 2013;3(2):374-391. doi:10.9734/AJEA/2013/2746

22. Martìnez JP, Ledent JF, Bajji M, Kinet JM, Lutts S. Effect of water stress on growth, $\mathrm{Na}+$ and $\mathrm{K}+$ accumulation and water use efficiency in relation to osmotic adjustment in two populations of Atriplex halimus L. Plant Growth Regul. 2003;41(1):63-73. doi:10.1023/A:1027359613325

23. Yuan XK, Yang ZQ, Li YX, Liu Q, Han W. Effects of different levels of water stress on leaf photosynthetic characteristics and antioxidant enzyme activities of greenhouse tomato. Photosynthetica. 2016;54(1):28-39. doi:10.1007/s11099015-0122-5

24. Mejri M, Siddique KHM, Saif T, Abdelly C, Hessini K. Comparative effect of drought duration on growth, photosynthesis, water relations, and solute accumulation in wild and cultivated barley species. J Plant Nutr Soil Sci. 2016;179(3):327-335. doi:10.1002/jpln.201500547

25. Mafakheri A, Siosemardeh A, Bahramnejad B, Struik PC, Sohrabi Y. Effect of drought stress on yield, proline and chlorophyll contents in three chickpea cultivars. Aust J Crop Sci. 2010;4(8):580-585.

26. Navari-Izzo F, Quartacci MF, Izzo R. Water stress induced changes in protein and free aminoacids in fieldgrown maize and sunflower. Plant Physiol Biochem. 1990;28(4):531-537.

27. Fathi A, Zahedi M, Torabian S. Effect of interaction between salinity and nanoparticles ( $\mathrm{Fe} 2 \mathrm{O} 3$ and $\mathrm{ZnO}$ ) on physiological parameters of Zea mays L. J Plant Nutr. 2017;40(19):2745-2755. doi:10.1080/01904167.2017.1381 731

28. Kheirizadeh Arough Y, Seyed Sharifi R, Sedghi M, Barmiki M. Effect of zinc and bio fertilizers on antioxidant enzymes activity, chlorophyll content, soluble sugars and proline in triticale under salinity condition. Not Bot Horti Agrobot Cluj Napoca. 2016;44(1):116-124. doi:10.15835/ nbha44110224

29. Sharma PN, Kumar N, Bisht SS. Effect of zinc deficiency on chlorophyll content, photosynthesis and water relations of cauliflower plants. Photosynthetica. 1994;30(3):353-359.

30. Zarrouk O, Gogorcena Y, Gómez-Aparisi J, Betrán JA, Moreno MA. Influence of almond $\times$ peach hybrids rootstocks on flower and leaf mineral concentration, yield and vigour of two peach cultivars. Sci Hortic. 2005;106(4):502-514. doi:10.1016/j.scienta.2005.04.011

31. Wang X, Yang X, Chen S, et al. Zinc oxide nanoparticles affect biomass accumulation and photosynthesis in Arabidopsis. Front Plant Sci. 2015;6:1243. doi:10.3389/ fpls.2015.01243

32. Gharibi S, Sayed-Tabatabaei BE, Saeidi G, Goli SAH. Effect of drought stress on total phenolic, lipid peroxidation, and antioxidant activity of Achillea species. Appl Biochem Biotechnol. 2016;178(4):796-809. doi:10.1007/s12010015-1909-3

33. Ghosh S, Chisti Y, Banerjee UC. Production of shikimic acid. Biotechnol Adv. 2012;30(6):1425-1431. doi:10.1016/j. biotechadv.2012.03.001

34. Kozlowski TT. Carbohydrate sources and sinks in woody plants. Bot Rev. 1992;58(2):107-222. doi:10.1007/ BF02858600

35. Ramachandra Reddy A, Chaitanya KV, Vivekanandan M. Drought-induced responses of photosynthesis and antioxidant metabolism in higher plants. J Plant Physiol. 2004;161(11):1189-1202. doi:10.1016/j.jplph.2004.01.013

36. Oloumi H, Soltaninejad R, Baghizadeh A. The comparative effects of nano and bulk size particles of $\mathrm{CuO}$ and $\mathrm{ZnO}$ on glycyrrhizin and phenolic compounds contents in Glycyrrhiza glabra L. seedlings. Indian J Plant Physiol. 2015;20(2):157-161. doi:10.1007/s40502-015-0143-x

37. Tavallali V, Rahemi M, Eshghi S, Kholdebarin B, Ramezanian A. Zinc alleviates salt stress and increases 
antioxidant enzyme activity in the leaves of pistachio (Pistacia vera L. 'Badami') seedlings. Turk J Agric For. 2010;34(4):349-359. doi:10.3906/tar-0905-10

38. Zago MP, Oteiza PI. The antioxidant properties of zinc: interactions with iron and antioxidants. Free Radic Biol Med. 2001;31(2):266-274. doi:10.1016/s08915849(01)00583-4

39. Jacob V, Rajiv P. In vitro analysis: the antimicrobial and antioxidant activity of zinc oxide nanoparticles from curcuma longa. Asian J Pharm Clin Res. 2019;12(1):200204. doi:10.22159/ajpcr.2019.v12i1.28808

40. Stan M, Popa A, Toloman D, Silipas TD, Vodnar DC. Antibacterial and antioxidant activities of $\mathrm{ZnO}$ nanoparticles synthesized using extracts of Allium sativum,
Rosmarinus officinalis and Ocimum basilicum. Acta Metall Sin-Engl. 2016;29(3):228-236. doi:10.1007/s40195-0160380-7

41. Senthilkumar N, NandhaKumar E, Priya P, Soni D, Vimalan M, Potheher IV. Synthesis, anti-bacterial, antiarthritic, anti-oxidant and in-vitro cytotoxicity activities of $\mathrm{ZnO}$ nanoparticles using leaf extract of Tectona grandis (L.). New J Chem. 2017;41(18):10347-56. doi:10.1039/ C7NJ02664A

42. Kumar B, Smita K, Cumbal L, Debut A. Green approach for fabrication and applications of zinc oxide nanoparticles. Bioinorg Chem Appl. 2014;2014:523869. doi:10.1155/2014/523869 